\title{
Reactions of Oxazolinium and Dihydrooxazinium Salts Prepared by an Azide Insertion Sequence: pH Control of Product Distribution
}

Jennifer E. Forsee, Brent T. Smith, Kristine E. Frank, and Jeffrey Aubé*

Department of Medicinal Chemistry, University of Kansas, Lawrence, Kansas 66045-2506, USA

Fax 1.785.864.4496; e-mail: jaube@ukans.edu

Received 6 August 1998

\begin{abstract}
The Lewis acid-promoted reaction between a ketone and an azido alcohol is an efficient route to imidate salts. The hydrolysis of these salts is shown to generate medium to large-ring lactams and lactones in good to excellent yield. The reaction products differ according to the $\mathrm{pH}$ of the medium used for hydrolysis of the imidate salts.
\end{abstract}

Imidate salts (iminium ethers) are ambident electrophiles that can be hydrolytically converted into a variety of useful products. ${ }^{1}$ Classically, these compounds have been prepared from the corresponding $N$ hydroxylalkyl amide through a formal dehydration procedure (Scheme 1). More recently, we have demonstrated that imidate salts can also be generated in situ by the Lewis acid-promoted reactions of hydroxy azides with ketones. ${ }^{2-4}$ The addition of nucleophiles to these imidate salts affords a range of products that includes amines, enamines and $\omega$ substituted alkyl amides. ${ }^{3}$ Globally, this mechanistically complex process can involve kinetic addition to the cationic center and proceed directly to product (path A) or involve displacement at the terminal carbon of the azido alcohol (starred, path B). ${ }^{1,3}$ In this paper, we show that lactones are also available from iminium ether hydrolysis and demonstrate that a measure of control can be imposed upon the reaction path (A1 vs. A2/B), resulting in enhanced utility of these heterocyclic intermediates in synthesis. In the special case of an $\alpha$-bromo substituted ketone, an interesting $\alpha$-amino ester synthesis is also described.<smiles>O=C1PCCCCCP1N(CO)CCO</smiles>
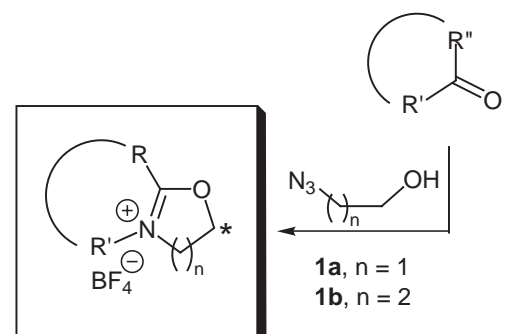<smiles>CCOC(=O)PC1CCCCCPN1</smiles>

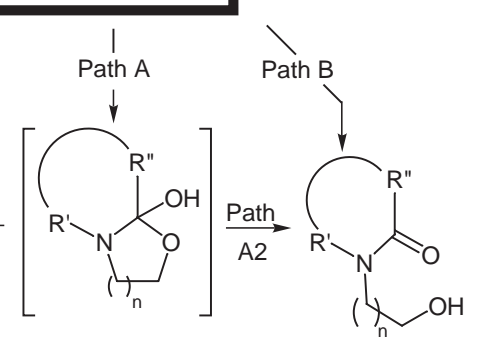

Scheme 1

Initial studies using cycloheptanone, $\mathbf{1 a}$ or $\mathbf{1} \mathbf{b},{ }^{5}$ and $\mathrm{BF}_{3} \cdot \mathrm{OEt}_{2}$ resulted in exclusive amide $\mathbf{2}$ formation when $\mathrm{KOH}$ was employed for imidate salt hydrolysis (Scheme 2). Alternatively, the use of $\mathrm{NaHCO}_{3}$ resulted in the formation of lactone $\mathbf{3}$ as the major product, in addition to the expected amide $2 .{ }^{6}$ Only amide formation was observed in our previous studies with four- to six-membered ring ketones, using either base in the work-up. ${ }^{2-4}$ The difference in transannular strain associated with the lactams (standard rings, 5-7 members) vs. lactones (medium rings, 8-11 members) formed in these cases most likely accounts for the absence of lactone production. In contrast, both products from the ring expansion of cycloheptanone contain medium-to-large rings and therefore, ring strain is likely to play a less dominant role in product selection.

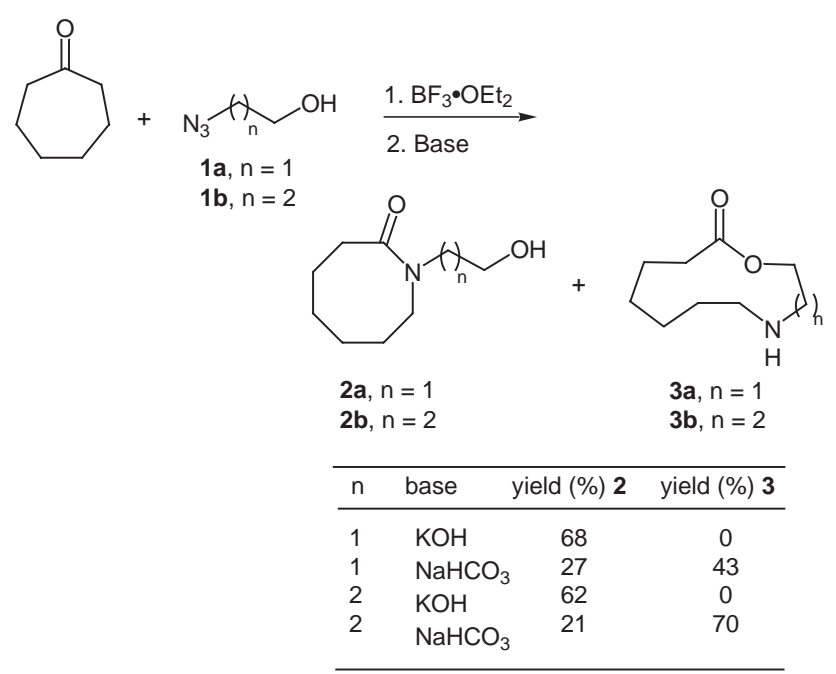

Scheme 2

Experiments with 5-nonanone and 1a (Scheme 3) illustrated similar behavior with respect to each work-up procedure, except that some ester was formed under both protocols. ${ }^{6}$ Although previously disclosed studies with acetone and $\mathbf{1 b}$ showed solely amide product in $86 \%$ yield when $\mathrm{NaHCO}_{3}$ was used, ${ }^{2}$ we have had difficulty in repeating this result. Current work to elucidate the effect of ketone and azide structures on the distribution of acyclic products is underway.

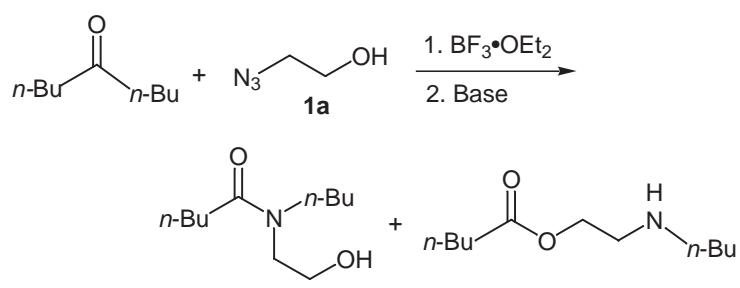

\begin{tabular}{|c|c|c|}
\hline 4 & & 5 \\
\hline base & yield (\%) 4 & yield $(\%) \mathbf{5}$ \\
\hline $\mathrm{KOH}$ & 55 & 28 \\
\hline $\mathrm{NaHCO}_{3}$ & 6 & 92 \\
\hline
\end{tabular}

Scheme 3

We decided to explore the reactivity and regiochemistry of the reaction with $\alpha$-bromocyclohexanone as substrate (Scheme 4). Amide (6) was produced under $\mathrm{KOH}$ or $\mathrm{NaOH}$ work-up, along with some alkene (7) resulting from elimination of $\mathrm{HBr}$. In this case, work-up with $\mathrm{NaHCO}_{3}$ 
resulted in the formation of a new product type, an $\alpha$-amino lactone (8). This latter product is explained by the mechanism outlined in Scheme 6 . In all cases, it is noteworthy that the less substituted methylene group undergoes predominant migration during the azido alcohol addition step.

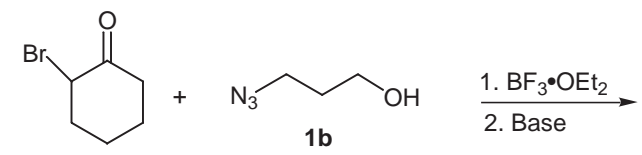<smiles>O=C1OCCCN2CCCCC12</smiles>

Scheme 4

We propose that the product distribution depends on the protonation state of intermediate B (Schemes 5 and 6). ${ }^{1,3}$ Two indistinguishable mechanisms are possible when the reaction is carried out in $\mathrm{KOH}$ or $\mathrm{NaOH}$ ( $\mathrm{pH}$ ca. 14). Distal attack of hydroxide ion on the linker carbon of A leads directly to amide. Alternatively, the reversible formation of intermediate $\mathbf{B}$ might also lead to amide by deprotonation in the strongly basic medium and collapse as shown (RO- being a better leaving group than $\left.\mathrm{R}_{2} \mathrm{~N}-\right)^{7}$

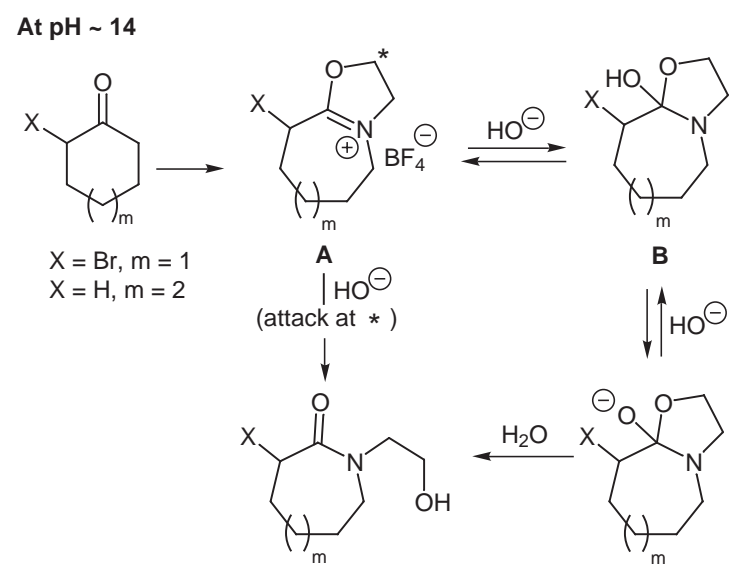

Scheme 5

In $\mathrm{NaHCO}_{3}$ (pH ca. 9), we propose that the reaction proceeds via protonated species $\mathbf{C}$ (Scheme 6). This is based on the expected $\mathrm{pK}_{\mathrm{a}}$ of the amine (ca. 10-11). ${ }^{7}$ For this species, preferential carbon-nitrogen bond cleavage occurs to give lactone as the major product. For $\alpha$ bromocyclohexanone, this explanation is reasonable if we also propose that the bromine is intramolecularly displaced by the amine once the macrocycle is formed, giving rise to 9. Importantly, the formation of lactones $\mathbf{3 a}, \mathbf{b}$ require the intermediacy of $\mathbf{B}$.

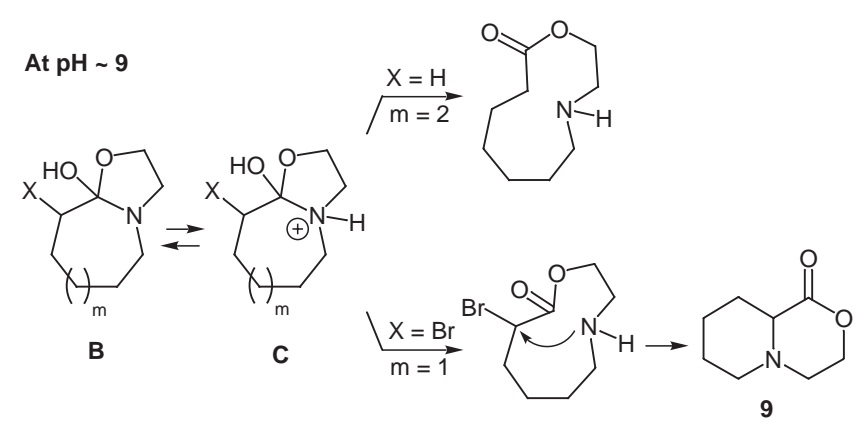

Scheme 6

In summary, we have devised a method for the synthesis of ringexpanded esters, amides, and their cyclic equivalents from ketones. Additionally, the choice of work-up conditions $\left(\mathrm{NaHCO}_{3}\right.$ vs. $\left.\mathrm{KOH}\right)$ permits moderate control of product outcome and reaction pathway. Application of this strategy to larger ring sizes and various $\alpha$-substituted ketones is under current investigation, as this methodology provides a means of obtaining products that may serve as possible amino acid and peptidomimetic precursors.

Acknowledgments: This work was supported by the National Institute of Health (GM-07775). K.E. Frank and J.E. Forsee gratefully acknowledge the Madison A. and Lila Self Fellowship Program for their support. The authors thank Martha D. Morton for assistance with NMR studies.

\section{References and Notes}

1. Hünig, S. Angew. Chem., Int. Ed. Engl. 1964, 3, 548-560.

2. Gracias, V. J.; Milligan, G. L.; Aubé, J. J. Am. Chem. Soc. 1995, 117, 8047-8048.

3. Gracias, V. J.; Milligan, G. L.; Aubé, J. J. Org. Chem. 1996, 61, 10-11.

4. Gracias, V. J.; Frank, K. E.; Milligan, G. L.; Aubé, J. Tetrahedron 1997, 53, 16241-16252.

5. For the preparation of $\mathbf{1 a}$ and $\mathbf{1 b}$, see: Badiang, J. G.; Aubé, J. J. Org. Chem. 1996, 61, 2484-2487.

6. Representative experimental details. (a) Preparation of 2a and 3a. Cycloheptanone $(0.200 \mathrm{~g}, 1.78 \mathrm{mmol})$ and $\mathbf{1 a}(0.170 \mathrm{~g}, 1.96$ mmol) were stirred in $\mathrm{CH}_{2} \mathrm{Cl}_{2}(20 \mathrm{~mL})$ at $0{ }^{\circ} \mathrm{C}$ for $20 \mathrm{~min}$, whereupon $0.53 \mathrm{~mL}$ of $\mathrm{BF}_{3} \cdot \mathrm{OEt}_{2}(0.612 \mathrm{~g}, 4.30 \mathrm{mmol})$ was added dropwise. After stirring for $1 \mathrm{~h}$, the solution was heated to reflux for $48 \mathrm{~h}$. After cooling, $15 \%$ aqueous $\mathrm{KOH}(10 \mathrm{~mL})$ or saturated aqueous $\mathrm{NaHCO}_{3}(10 \mathrm{~mL})$ was added over $5 \mathrm{~min}$, and the resulting mixture was stirred for $24 \mathrm{~h}$. The reaction mixture was then extracted with $\mathrm{CH}_{2} \mathrm{Cl}_{2}(2 \times 100 \mathrm{~mL})$ and ether $(3 \times 100 \mathrm{~mL})$. The organic extracts were combined, dried over $\mathrm{MgSO}_{4}$, and filtered. Concentration and silica gel chromatography afforded 2a and 3a, respectively.

For 2a: $205 \mathrm{mg}$ of a white solid, $67 \%$ yield; $\mathrm{mp} 79-81{ }^{\circ} \mathrm{C} ;{ }^{1} \mathrm{H}$ NMR (400 MHz, $\left.\mathrm{CDCl}_{3}\right) \delta 1.56(\mathrm{~m}, 4 \mathrm{H}), 1.68(\mathrm{~m}, 2 \mathrm{H}), 1.81(\mathrm{~m}$, $2 \mathrm{H}), 2.54(\mathrm{t}, J=6.3 \mathrm{~Hz}, 2 \mathrm{H}), 3.53(\mathrm{t}, J=5.3 \mathrm{~Hz}, 4 \mathrm{H}), 3.79(\mathrm{~m}$, $2 \mathrm{H}), 3.86(\mathrm{~s}, 1 \mathrm{H}) ;{ }^{13} \mathrm{C}$ NMR $\left(75.6 \mathrm{MHz}, \mathrm{CDCl}_{3}\right) \delta 24.3,26.2$, 28.6, 29.3, 34.0, 49.1, 50.0, 62.8, 177.4; IR (neat) 3330, 2905, 2820, $1610 \mathrm{~cm}^{-1}$; MS (EI) $\mathrm{m} / \mathrm{e} 171\left(\mathrm{M}^{+}\right), 153,141,55$; HRMS calcd for $\mathrm{C}_{9} \mathrm{H}_{18} \mathrm{NO}_{2}\left(\mathrm{M}^{+}+\mathrm{H}\right): 172.1338$, found 172.1325 .

For 3a: $134 \mathrm{mg}$ of a crystalline solid, $43 \%$ yield; $\mathrm{mp} 81-82{ }^{\circ} \mathrm{C} ;{ }^{1} \mathrm{H}$ NMR (400 MHz, $\left.\mathrm{CDCl}_{3}\right) \delta 1.42-1.59(\mathrm{~m}, 7 \mathrm{H}), 1.82(\mathrm{~m}, 2 \mathrm{H}), 2.39$ 
(m, 2H), $2.68(\mathrm{t}, J=4.4 \mathrm{~Hz}, 2 \mathrm{H}), 2.94(\mathrm{t}, J=4.7 \mathrm{~Hz}, 2 \mathrm{H}), 4.22(\mathrm{t}$, $J=4.8 \mathrm{~Hz}, 2 \mathrm{H}) ;{ }^{13} \mathrm{C} \mathrm{NMR}\left(100.6 \mathrm{MHz}, \mathrm{CDCl}_{3}\right) \delta 24.7,26.6$, 29.0, 29.8, 34.4, 49.6, 50.6, 63.3, 177.9; IR $\left(\mathrm{CH}_{2} \mathrm{Cl}_{2}\right)$ 3340, 2920, $1715 \mathrm{~cm}^{-1}$; MS (CI) m/e $172\left(\mathrm{M}^{+}+\mathrm{H}\right)$; HRMS calcd for $\mathrm{C}_{9} \mathrm{H}_{18} \mathrm{NO}_{2}\left(\mathrm{M}^{+}+\mathrm{H}\right): 172.1337$ found 172.1348.

(b) Compound $\mathbf{8}$ was prepared as described above $\left(\mathrm{NaHCO}_{3}\right.$ method) except reaction was run at room temperature: $148 \mathrm{mg}$ of an oil, $67 \%$ yield; ${ }^{1} \mathrm{H}$ NMR $\left(100.6 \mathrm{MHz}, \mathrm{CDCl}_{3}\right) \delta 1.47-1.90(\mathrm{~m}$, $6 \mathrm{H}), 1.92-2.12(\mathrm{~m}, 2 \mathrm{H}), 2.49(\mathrm{dt}, J=11.7,4.5 \mathrm{~Hz}, 1 \mathrm{H}), 2.71(\mathrm{~m}$,
1H), 2.97 (ddd, $J=14.4,11.7,4.5 \mathrm{~Hz}, 1 \mathrm{H}), 3.13(\mathrm{~m}, 1 \mathrm{H}), 3.63(\mathrm{t}$, $J=4.2 \mathrm{~Hz}, 1 \mathrm{H}$ ), 4.16 (ddd, $J=12.3,9.3,1.8 \mathrm{~Hz}, 1 \mathrm{H}$ ), 4.49 (qq, $J=$ 12.0, 6.3 Hz, 1H); $\left.{ }^{13} \mathrm{C} \mathrm{NMR} \mathrm{(100.6} \mathrm{MHz,} \mathrm{CDCl}_{3}\right) \delta 20.6,25.9$, 26.7, 28.6, 50.5, 56.6, 62.6, 67.8, 174.9; IR (neat) 2925, $1720 \mathrm{~cm}^{-}$ ${ }^{1}$; MS (CI) m/e $170\left(\mathrm{M}^{+}+\mathrm{H}\right), 142,124,97,83$; HRMS calcd for $\mathrm{C}_{9} \mathrm{H}_{16} \mathrm{NO}_{2}\left(\mathrm{M}^{+}+\mathrm{H}\right): 170.1175$, found 170.1181 .

7. Deslongchamps, P. Stereoelectronic Effects in Organic Chemistry; 2 ed.; Pergamon Press: Oxford, 1983; Vol. 1, pp 101162. 